\title{
Mapeamento de derivações por variáveis sintéticas na Peça para dois minutos de Guerra-Peixe
}

\author{
Mapping of derivations by synthetic variables in Peça para dois minutos \\ by Guerra-Peixe
}

Hanon Guy Lima Rossi

Universidade de São Paulo (PPGMUS-ECA)

\author{
Adriana Lopes Moreira \\ Universidade de São Paulo (PPGMUS-ECA)
}

\begin{abstract}
Resumo: Peça para dois minutos, de Guerra-Peixe, obra serial para piano solo, é o objeto de estudo da presente análise. Motivos recorrentes foram observados, de modo que surgiu o interesse em desvelar as técnicas de recorrência de ideias, desenvolvimento e estruturação. Chegou-se à conclusão de que a obra possui um pequeno motivo onipresente, e que ela se afasta da estrutura mais fechada do dodecafonismo. Os métodos utilizados envolveram a análise motívica de Schoenberg, a análise tradicional de variações, parte da técnica das "variáveis sintéticas" (desenvolvida por um dos autores), e uma parte restrita da teoria dos conjuntos.
\end{abstract}

Palavras-chave: Música do século XX. Análise musical. Piano. Atonalismo serial. César Guerra-Peixe.

\begin{abstract}
Two-Minute Piece", by Guerra-Peixe, serial work for solo piano, is the object of study in this current analysis. Recurring motifs were observed, in such way that prompted the curiosity to discover the techniques for recurring ideas, development and structuring. A conclusion came that the work has got a small omnipresent motif, and it also gets rid of the more rigid structure of dodecaphonism. The methods used were the motivic analysis by Schoenberg, the traditional analysis of variations, part of the technique of "synthetic variables" (developed by one of the authors), and a restricted part of the Set-Theory.
\end{abstract}

Keywords: Twentieth-Century Music. Musical analysis. Piano. Serial atonality. Cesar Guerra-Peixe. 
Guerra-Peixe, durante a década de 40, e enquanto parte do Grupo Música Viva, procurava se firmar ao dodecafonismo. Contudo, já iniciaria a década de 50 abandonando a técnica alemã em prol de um nacionalismo, este possivelmente vindo como consequência de uma reflexão orientada à adesão da arte às camadas populares, tendência do espectro político da esquerda que se fazia presente no Grupo Música Viva (cf. Barros 2013, p. 50). “Ao longo de sua vida, César Guerra-Peixe (1914-1993) passou por várias fases composicionais. Desde o fim dos anos 1940 ele começou a flexibilizar o dodecafonismo que praticara nos anos anteriores, de modo a torná-lo mais 'compreensível para o auditório'" (Guerra-Peixe 1949, apud Barros 2013, p.11). A partir disso podemos pressupor uma transição, dentro da qual alguns tipos de tentativas mais libertas da rigidez do sistema dodecafônico apareceriam em algumas de suas peças. É o caso da Peça para dois minutos (1947), cujas traduções em inglês e alemão (Twominute Piece e Zwei-Minuten-Stück) sugerem que o título não contenha nenhuma razão programática externa, e realmente se trate de um estudo puro de técnicas seriais ao piano, pressuposto a durar dois minutos e de caráter bastante objetivo.

A partir da Peça para dois minutos, elabora-se uma hipótese inicial, de onde surge a impressão de que um simples motivo estaria estruturando a obra em sua completude, e posto em variações diversas e concatenadas. Para comprovar tal hipótese, considera-se como melhor recurso o uso de parte de uma técnica analítica desenvolvida durante o mestrado de um dos autores, a de "variáveis sintéticas" (cf. Rossi 2019), que por sua vez surge como uma continuidade da técnica de demarcação motívica que Schoenberg apresenta em Fundamentos da Composição Musical (Schoenberg 2008, p. 35, 39, Exs. 15-16). Esse recurso também guarda fortes relações com o tradicional método de análise de Fugas, a partir do qual Sujeito, Contrassujeito e possíveis derivações (estas surgindo em episódios, sequências etc.) são demarcados em todas as vozes ${ }^{1}$.

A explicação parcial da técnica de "variáveis sintéticas" precisa ser feita aqui, de forma a dar sentido ao prosseguimento da análise. Este recurso envolve um rastreamento de todas as conformações motívicas de uma peça, e a atribuição de símbolos matemáticos aos materiais, aos processos composicionais desenvolvidos durante uma peça, aos processos de derivação musical e aos

\footnotetext{
1 Para verificar apenas dois dos inúmeros exemplos de publicações deste tipo de análise, cf. Zamacois (2007, p. 57) e Sampson (1911).
} 
processos de variação, tal qual ocorre com funções algébricas, o que pode gerar um pequeno número de "equações" de equivalência (que serão exemplificadas mais adiante). Portanto, os materiais podem surgir com as caracterizações "z1", "z2" etc., onde a letra será de livre escolha, mas a numeração do material denota uma ordem de aparição na peça. Os processos composicionais que poderiam ser incluídos são diversos, desde os fraseológicos (como condensação e liquidação, cf. Schoenberg 2008, p. 59), até outros que poderiam ser identificados na forma, nas texturas, nos contrastes e em outros parâmetros. Seccionar trechos maiores de uma peça e rotular também faz parte da própria tradição analítica, e esses procedimentos poderiam também ser aplicados à técnica de mapeamento (como identificação de temas principais e subordinados, episódios, desenvolvimentos etc.). Quando as derivações implicam operações comuns, tais como retrogradação (disposição do material linear pela leitura de direção contrária, do final para o início), inversão (direção invertida dos intervalos ocorrentes em um material linear), aumentação (aumentar os valores rítmicos de uma linha), ampliação (alongamento do "fraseio" do material linear por técnicas diversas, a serem especificadas na ocasião) e fragmentação (recorte de um trecho do material linear original), elas assumem as notações R[a1], I[a1], Aum[a1], Amp[a1] e F[a1], respectivamente, feitas sobre o material a1. Para derivações que envolvam dois ou mais processos, eles podem se juntar, dando origem assim a expressões como em R[I[a1]], que por sua vez podem eventualmente ser simplificadas (para RI[a1] neste caso, visto que IR[a1] geraria o mesmo resultado) ${ }^{2}$. Diversos procedimentos de variação podem caber nesta notação, à escolha de quem efetuar as análises. Para derivações menos óbvias, a notação empregada genericamente é a de V[a1] (a letra V para "variação"), eventualmente precisando ser explicada quando citada.

Nesta peça a ser analisada, em particular, poder-se-á verificar ao final a falta de necessidade de se designar muitos símbolos aos seus materiais diversos, sendo, portanto, esta técnica utilizada sem o aproveitamento completo de suas potencialidades.

\footnotetext{
${ }^{2}$ As derivações não levam em conta transposições exatas (utilizando-se assim a mesma notação para repetições transpostas de materiais), mas um sistema de simbolizar e sintetizar as transposições pode ser desenvolvido por um musicólogo que julgar relevante para o seu trabalho (embora não para a presente peça).
} 


\section{Parte A (c. 1-30)}

O Allegro (alla breve) é a primeira parte de uma forma $\mathrm{ABA}^{\prime}$, em que a recapitulação de A conserva alguns perfis, o padrão rítmico, e algumas linhas ou contornos. A parte A mantém frases prioritariamente em legato, com conjuntos de quatro ou seis notas, enquanto a entrada da parte B é marcada em seu início pela ausência do legato; ambas são finalizadas por um perfil de rítmica identificada com brasilidade, com staccatos na região grave. Apesar de surgirem eventualmente transposições exatas de curtas linhas, a variedade do cromatismo e das intercorrências harmônicas é tão grande que não aparenta seguir um padrão à primeira vista, tanto para conjuntos empregados quanto para um possível contexto serial. Destaque foi dado somente para fenômenos de recorrência harmônica mais flagrantes, que se repetem e que são facilmente identificados.

A peça começa em dobramento das mãos à distância de duas oitavas exatas. O motivo “a1" (Fig. 1, c. 1), de três notas em zigue-zague, das quais a segunda é alcançada por salto ascendente, e a terceira posta um grau conjunto acima da primeira, é de fato o primeiro motivo da peça, e também se revelará ao final como o "DNA" de todas as linhas. A pequena variante em que o salto é de terça, e não de quarta, não sinaliza mudança de contorno relevante o suficiente para caracterizar uma variação. Relevante é o V[a1] do $3^{0}$ compasso, em que os intervalos se expandem e o perfil de grau conjunto se perde. Poderíamos talvez aventar o delineado da tríade como uma influência de uma ocorrência inesperada da dupla concatenação de a1 tal qual exposto inicialmente (com o círculo oval intermitente, mostrando três notas que formam a tríade maior, e direcionando por setas para V[a1] (Fig. 1). No c. 4, G\#-D\#-F\# caracterizam uma $\mathrm{I}[\mathrm{a} 1]$, visto que a mudança de uma só nota $(\mathrm{G} \#)$ para a oitava de baixo, apesar de alterar o contorno, não desfaz o laço de derivação direta. Essa I[a1] é expandida até a nota $\mathrm{E}$, mostrando-se consequentemente uma Amp[I[a1]], que se revela importante o suficiente para ser caracterizada como um motivo secundário novo, "b1", e assim gerando um tipo de "equação" de equivalência (Amp[I[a1]] = b1), a partir da qual podem ser desenvolvidas obras com as "developing variations" (cf. Schoenberg 1950, p. 39), técnica que invariavelmente produziria as equações de 
equivalência em grandes quantidades. O perfil intervalar de b1, $(0135)^{3}$, com quatro notas em zigue-zague e na ordem em que aparece (G\#-D\#-F\#-E, oitavações e transposições exatas), é mantido diversas vezes em que b1 retorna, de maneira que julgar-se-ia importante demarcar mesmo as mínimas alterações de intervalos por V[b1] (e é passível de argumento, antecipadamente, que o perfil de b1 seja tão significativo, por tanta reiteração, que até se disponha harmonicamente como fechamento da seção B, c. 42, tal qual será visto mais à frente).

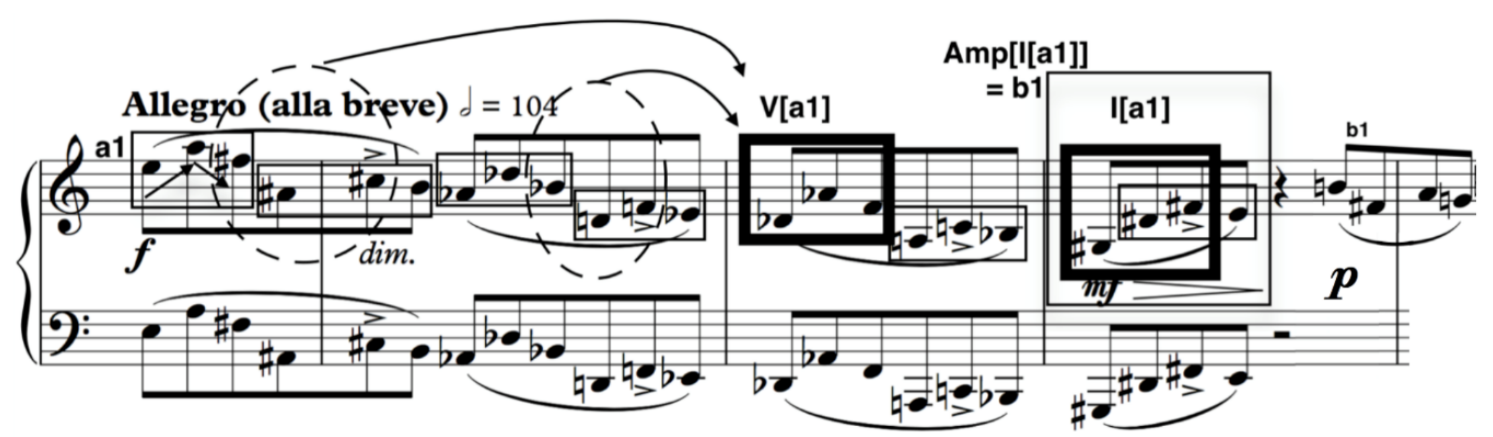

Figura 1: Motivo, derivações e variação no início da parte A. Guerra Peixe, Peça para dois minutos (c. 1-4) .

No c. 5, a mão esquerda apresenta uma ampliação de b1 (Fig. 2) que, embora aconteça mais vezes, não recorre consistentemente aos mesmos intervalos, e nem demonstra importância motívica especial. O mais significativo do trecho é o intervalo quartal G-C-F, marcado em círculo oval, cujo padrão harmônico é marcante e recorrente na obra. Com alguma frequência ainda aparecerá ao longo da análise (demarcado por círculos), como ocorre no c. 8, onde surgem $D \#-G \#-C \#-F \#-B-E$ na mão direita, e na esquerda, G-C-F-Bb. A "imitação harmônica", da mão esquerda "respondendo" à mão direita, ocorre não somente no c. 8, mas também nos c. 9-10.

\footnotetext{
${ }^{3}$ Notação pela Teoria dos Conjuntos feita por conveniência. Para uma introdução à notação, cf. Kostka (2018) e Straus (2016).

${ }^{4}$ A edição desta partitura é de autoria de Hanon Rossi, em todas as ilustrações. A obra pode ser ouvida e vista com a partitura original no seguinte endereço eletrônico: https://www.youtube.com/watch?v=QzF4bAKkrKI
} 

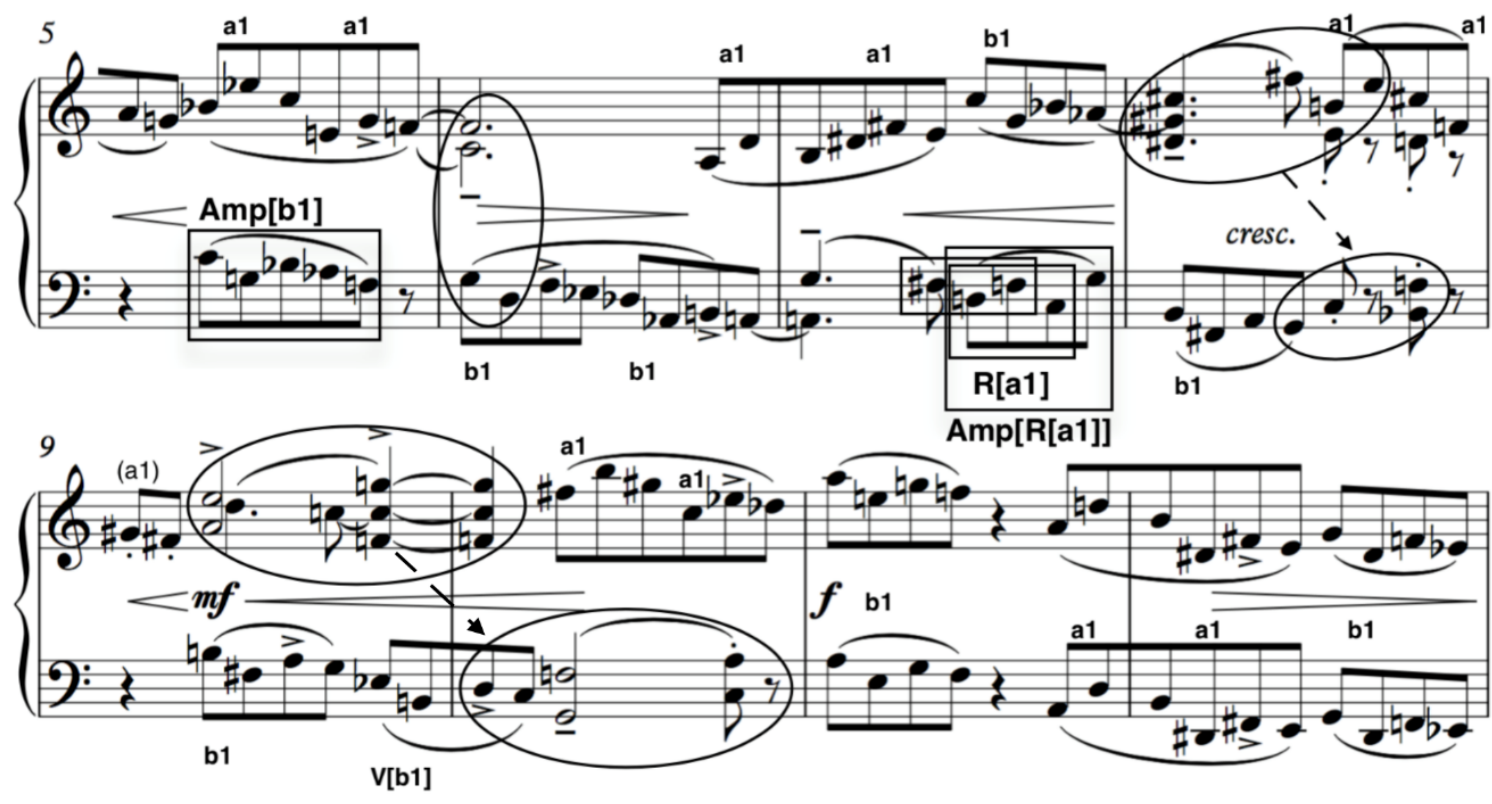

Figura 2: Ocorrências variadas de b1. Guerra Peixe, Peça para dois minutos (c. 5-12).

No c. 7 (Fig. 2) também ocorre na mão esquerda, brevemente, um tipo de derivação que vai se tornar mais comum com o desenvolvimento da peça; tratase de uma sobreposição de derivados de a1 por elisão, de forma que a figuração em zigue-zague se torna a sua principal característica, sem personalidade motívica marcante.

A esta altura, ao se conferir a Fig. 2, fica evidente como b1 é empregado continuamente sem grandes variações, e frequentemente após aplicações de a1, como ocorre no início da peça (c. 4). As primeiras variações de b1 são cautelosas, como a alteração em apenas meio-tom no c. 9, V[b1] (Fig. 2), gerando (0134), que em situações normais não seria uma variação significativa o suficiente para ser notada nem renomeada (tanto que as variedades intervalares de a1, por serem mais comuns, não parecem em geral merecer renomeações). Novamente surgem as instâncias quartais, na mão direita com E-A-D-G-C-F, e na esquerda com AD-G-C-F. Os c. 11 e 12 são de identificação trivial, visto que o dobramento a duas oitavas de distância entre as claves realiza, em ordem: b1, a1, a1, b1. Mais do que isso, eles retornam a textura do início da peça, e parcialmente a estrutura, indicando aparentemente um possível perfil principal, de função praticamente temática.

Um indício de que um desenvolvimento se inicia em seguida (Fig. 3, c. 13) é que, logo após o surgimento da linha inicial, com as mesmas notas do começo, 
há a vinda de derivações de caráter mais complexo. Essas derivações caracterizam-se tanto pela ampliação da figura de a1 (que no c. 14 se apresenta com intervalos também um pouco distintos dos habituais para a1 e variações até então), quanto pelo descrito no c. 15, onde os grupos ligados de quatro notas demarcam variações e ampliações não-triviais de a1 e b1, e marcam conjuntos harmônicos distintos (sendo os quatro conjuntos do c. 15 distintos, formando, com Bb-D-F-Eb, um Bb maior com 4⿳âj adicionada [add4], e em G\#-C\#-B-D\# um G\# menor add4, e com F\#-E-G-C um C maior com $4^{a} A$ adicionada [add4+], e por fim com $\mathrm{A} b$-Eb-D-B um $\mathrm{A} b$ menor add4+). Contudo, essas linhas podem ser recortes de certas linhas antecessoras: $\mathrm{B} b$-D-F-Eb vêm da $5^{\mathrm{a}}$ à $8^{\mathrm{a}}$ nota do c. 2, por exemplo, enquanto G\#-C\#-B-D\# pode vir do contorno de B-E-C\#-F do c. 8. De fato, são rastreáveis muitas influências nas derivações destes grupos de 4 notas do c. 15, tanto na escolha de harmonias quanto de contorno. Mais uma observação de interesse surge da tesis (primeiro tempo forte) do c. 15, onde se encontra circulado um acorde quartal parcial (Fig 3), em que faltariam $G$ entre $D$ e $C$ na mão esquerda, e $\mathrm{F}$ abaixo do $\mathrm{Bb}$ na mão direita. As derivações harmônicas começam a dar indícios de liberdade maior, se distanciando da aderência exclusiva à disposição original (mais uma evidência do começo de um desenvolvimento factual).

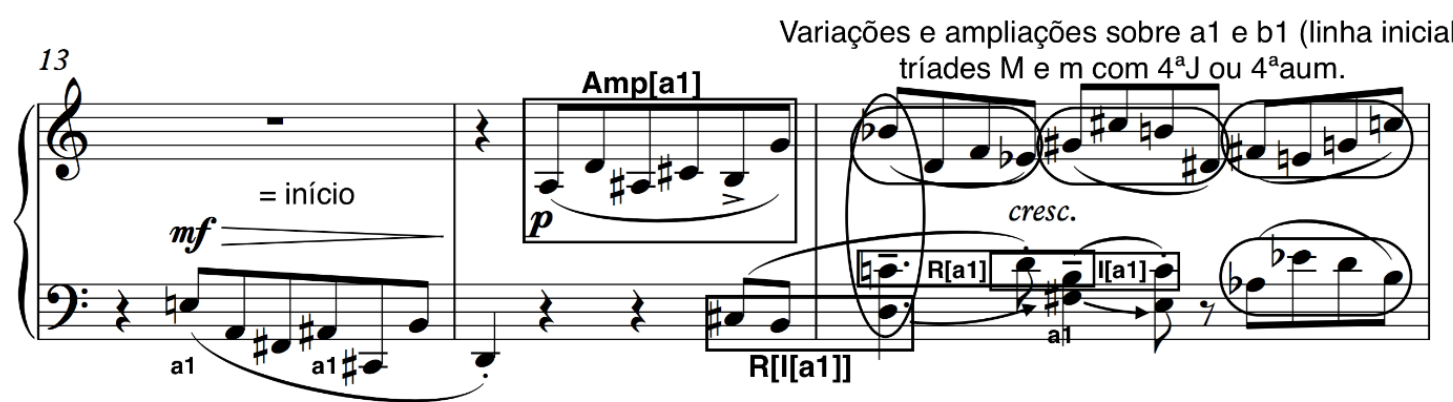

Figura 3: Início de um desenvolvimento. Guerra Peixe, Peça para dois minutos (c. 13-15).

A cabeça do c. 16 é mais um acorde quartal incompleto, disposto com as notas de baixo para cima por quartas sobrepostas em ordem exata, de D a Eb (D\# na partitura) tal qual na cabeça do c. 15, com divergência nas notas faltantes, não sendo o mesmo conjunto idêntico. Os outros círculos ovais (não confundir com os grupos de derivações complexas V[I[b1]] da mão esquerda, Fig. 4) demarcam também acordes quartais, mas não mais em sua disposição mais básica na tessitura (a de quartas sobrepostas de baixo para cima). Algumas variantes nas linhas do c. 17, como V[a1] na mão esquerda, e também na voz mais aguda da 
mão direita, aparentam surgir não por um plano coerente de estrutura em meio à peça toda, mas por conveniência local de encaminhamento das notas (neste caso talvez desviando ao $\mathrm{F}$ para não repetir o $\mathrm{D}$ da mão direita, como seria se seguisse as seis notas do começo da peça, que perfazem uma célula importante e frequentemente repetida).

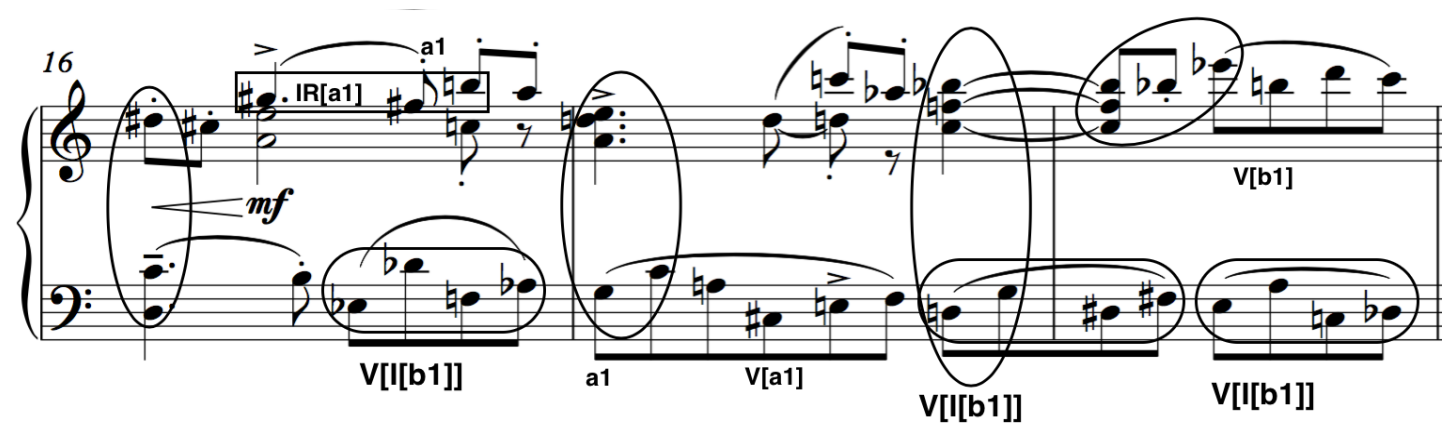

Figura 4: Formação de acordes quartais. Guerra Peixe, Peça para dois minutos (c. 16-18).

A Fig. 5 demonstra os momentos finais da parte A: o caminho ao ponto culminante, seguido por sua dissolução. Os acordes quartais aparecem eventualmente, mas não com tanta frequência e duração; a recapitulação de A é onde se encontrará uma alteração nesta paleta harmônica. $\mathrm{O}$ mais chamativo nesta ilustração, além do processo todo de chegada ao clímax em ff do c. 24 e na dissolução consequente, é a entrada de uma linha com ares mais próximos aos de uma melodia cantabile, modal e em tempo estendido. Antes disso, as únicas vezes em que havia um relaxamento do tempo de colcheias era em pontuações de acordes (quase todos eles quartais), e eventualmente em algum staccato. Existem antecedentes dessa textura nesses acordes: uma linha mais estendida aparece na nota superior dos acordes (portanto advinda deles), embora nestes casos ela se mostrasse com muito menos destaque, bem mais curta e quase sempre na mão esquerda. Esta melodia do c. 24 também é acompanhada de uma figuração percutida de rítmica característica, brasileira, que nesta função de "acompanhamento" se torna a novidade da peça até então, antes puramente contrapontística ou em linhas oitavadas. Contudo, ela aparece pouco, pois se presta à dissolução da energia acumulada. Isto é uma solução pianística clássica, visto que o martelar de acordes, ainda por cima tão ao grave (na nota mais grave da peça até o momento), tem mais potencial para intensidade e volume. 
Visualizamos assim um exemplo de um recurso de alteração textural como forma de aproveitar a possibilidade do contraste, em prol de uma função composicional: a demarcação de seções distintas.
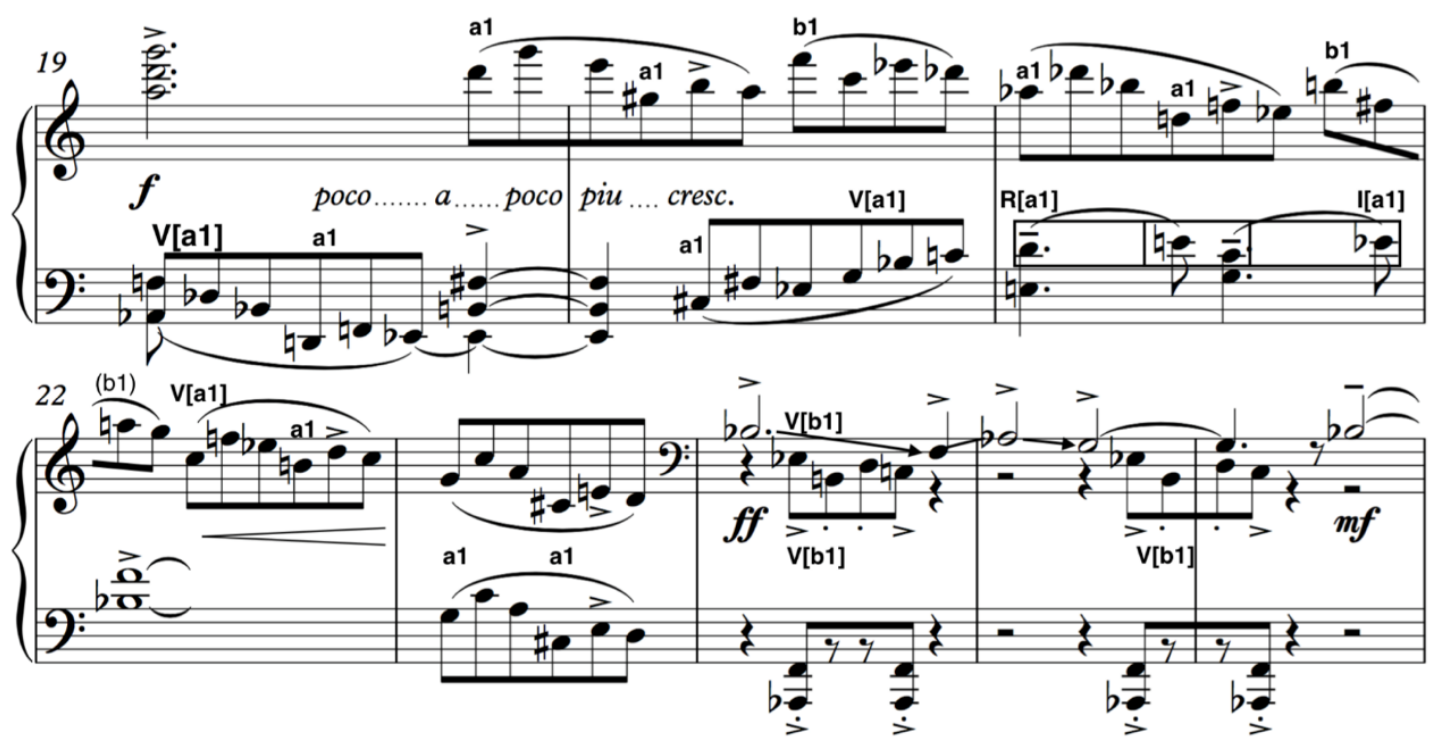

Figura 5: Final da parte A. Guerra Peixe, Peça para dois minutos (c. 19-26).

\section{Parte B (c. 31-42)}

A parte B, Molto meno, representa uma seção contrastante "lírica", ou ao menos mais lenta e calma, e caracteriza-se pela aumentação dos valores rítmicos dos motivos, assim aproximando-os um pouco mais a um caráter vocal, de entoação melódica.

Contudo, a parte $\mathrm{B}$ em geral mantém as características originais de grande parte dos motivos, visto que a maior parte das transformações são de aumentação, inversão e retrogradação, que a rigor não alteram o conjunto de intervalos e nem o zigue-zague característico dos motivos. Variações mais complexas do que a mera ampliação das linhas seriam visíveis mais nos últimos quatro compassos da parte $\mathrm{B}$, porém são referência imediata à brasilidade no final da parte A (os c. 24-26 são análogos aos c. 40-42). Um detalhe de harmonia interessante é visto no c. 42, onde o conjunto de b1, (0135), aparece na forma harmônica, e não mais somente na horizontal (através de G\#-A-B-C\#). Este acorde é o fechamento da seção, e também parece confirmar a importância de "b1" 
enquanto célula menos sujeita a transformações, com seu conteúdo intervalar mantido intacto.
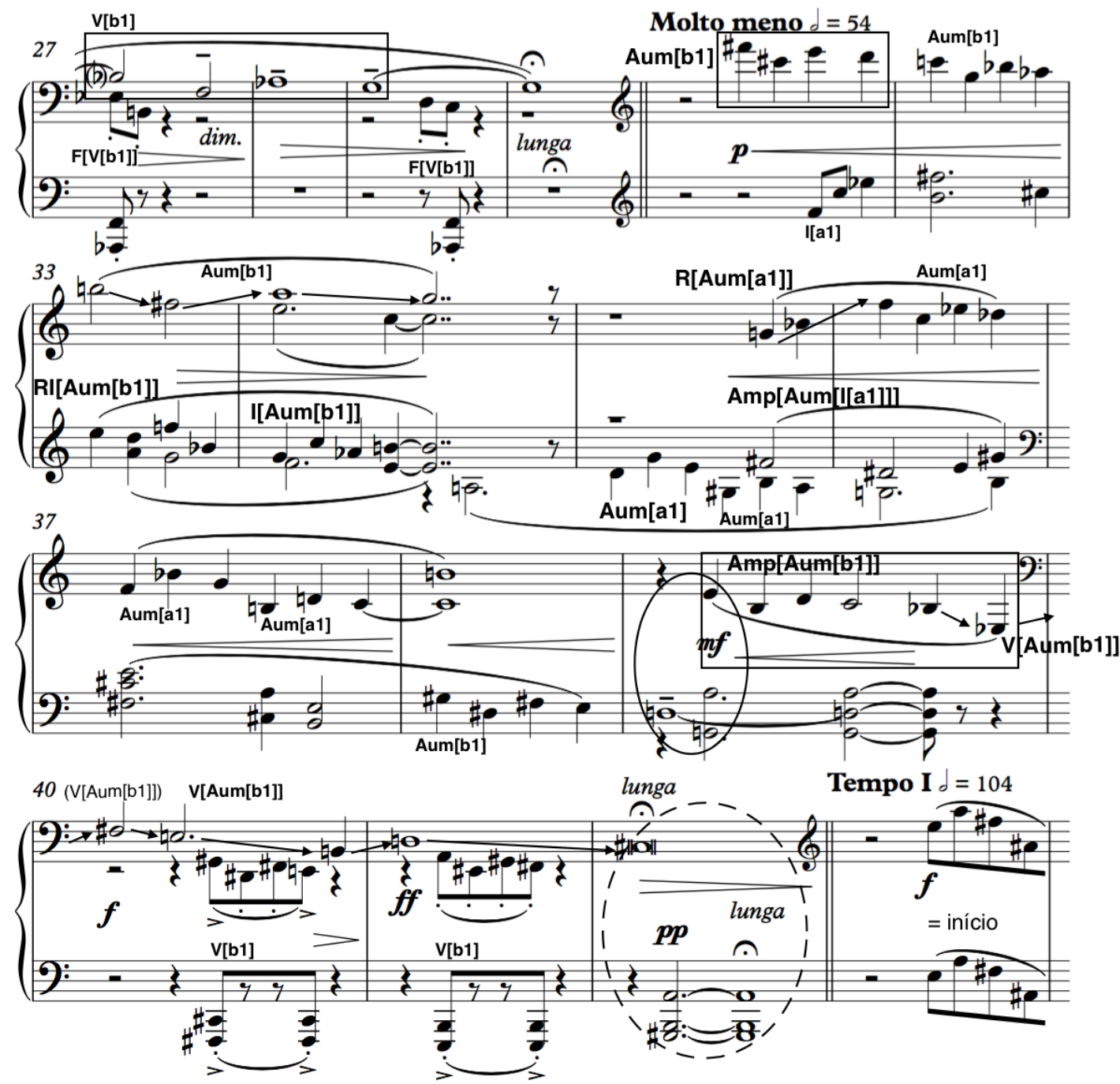

Figura 6: Parte B (c. 30, Molto meno) e início da recapitulação da parte A (c. 43, Tempo I). Guerra Peixe, Peça para dois minutos (c. 27-43).

\section{Recapitulação modificada da parte A (A', c. 43-61)}

A recapitulação da parte A é feita ipsis litteris por um pouco mais do que quatro compassos, mas a continuação não deixa de insistir na célula de seis notas ligadas, sempre resultante da concatenação de dois "a1" distintos, que é como a obra de fato se inicia, e por cuja figura há predileção durante o correr da parte A. De fato, é possível perceber que quase todas as células de seis notas ligadas são 
compostas de dois "a1", tal qual no início, e que quase todas as células de quatro notas ligadas são "b1" ou seus derivados. As variações de a1 que aparecem na mão esquerda, dos c. 48-50 (Fig. 7), estão relacionadas com as pontuações de acordes da parte A também, pois usam a semínima pontuada na melodia que erige do acorde, rítmica característica de quase todas melodias que os acordes sublinham da parte A nas mãos direita (c. 8, 9, 16, 17) e esquerda (15 e 21).
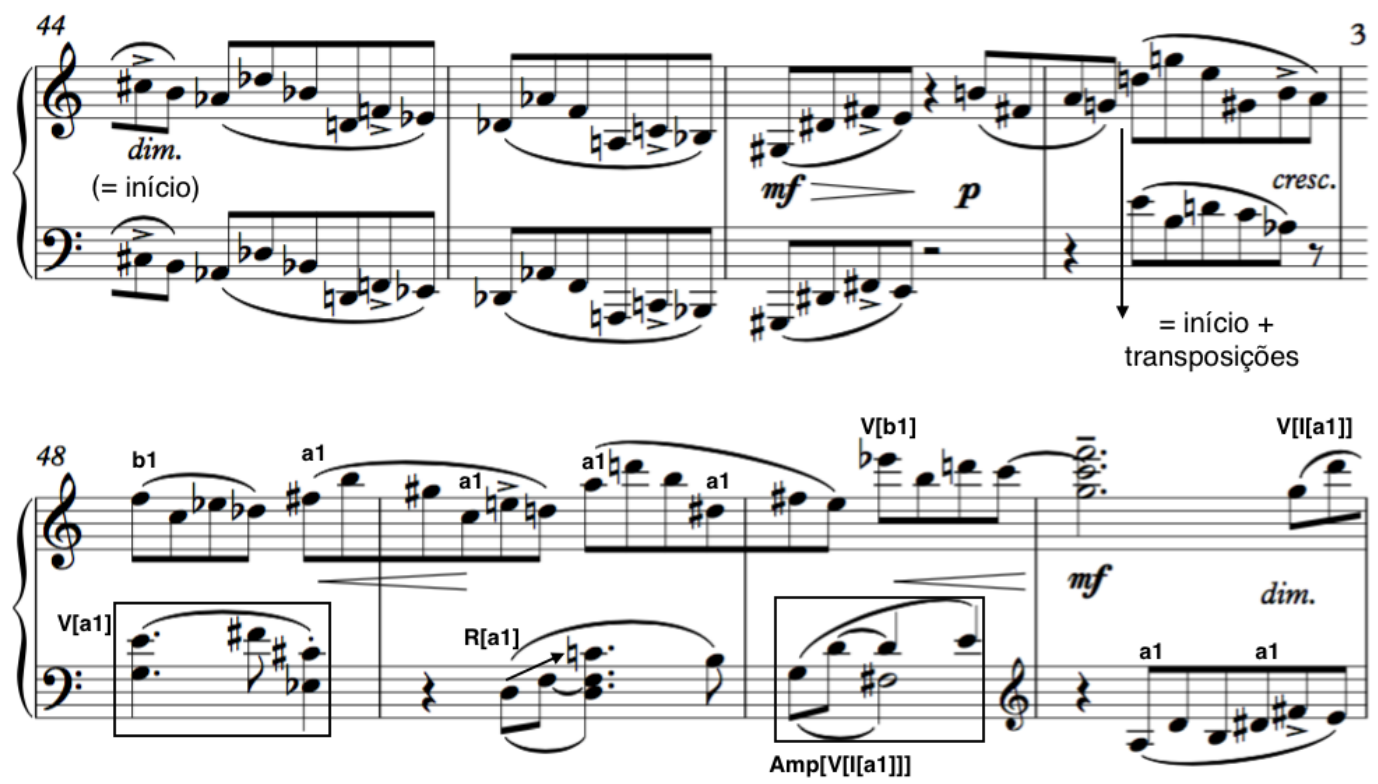

Figura 7: Recapitulação da Parte A. Guerra Peixe, Peça para dois minutos (c. 44-51).

Os momentos finais indicam diversas idiossincrasias, como alguns acordes quartais particulares, e um encaminhamento ao extremo agudo, além de certa diluição de figuras. No caso dos acordes quartais, eles abarcam, em dois momentos, também a possibilidade da $4^{\mathrm{a}}$ aumentada, como acontece no c. 52 (Fig. 8), Eb-Ab-Db-(G)-C-F (G faltando, processo de ocultação de notas de acordes já visto antes), e no c. 53, com F-B-E-Bb-Eb-Ab, em ambos os casos dispostos naquela exata ordem de quartas sobrepostas de baixo para cima. Vemos assim uma ligeira transformação de paradigma harmônico desses acordes. Outro ponto de interesse, além do extremo agudo, são as linhas em ininterrupto zigue-zague, dos c. 53-56, resultados de elisão constante de motivos "a1". Também chama atenção a diluição nas linhas dos c. 55-56 (onde aparece até F[b1], cf. Fig. 8), assim como as fragmentações nos c. 59-60, sendo que as fragmentações do c. 59 podem também ser interpretadas como como F[b1] (especificamente daquele b1 original, o primeiro, do c. 4), além da última célula (c. 60), que se constitui como uma 
transposição fragmentada da primeira célula de seis notas. A peça termina na mesma nota em que começa, e com a repetição da nota à distância rítmica de semínima pontuada, tal qual nos "acompanhamentos" dos c. 24-26 e 40-41.
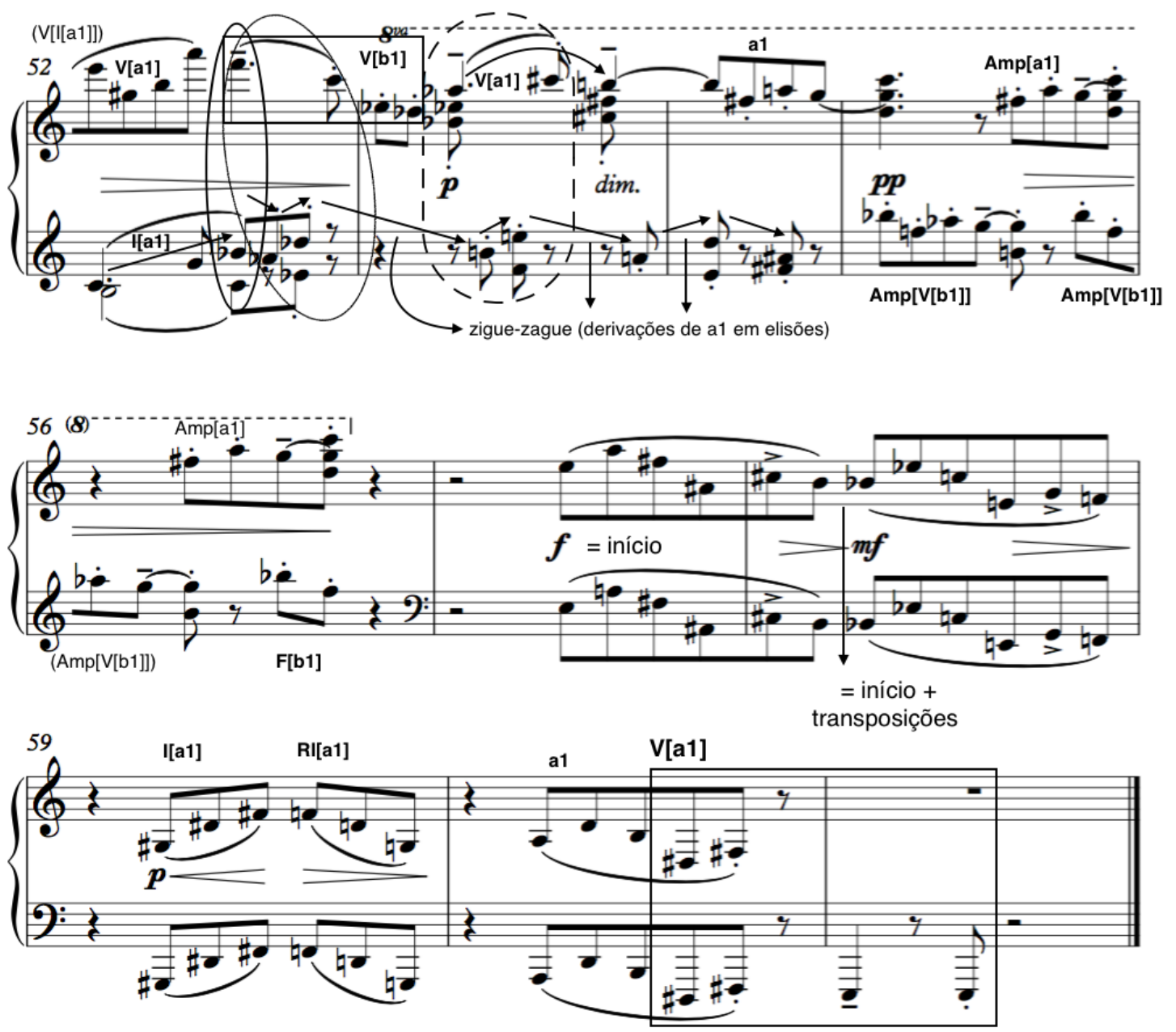

Figura 8: Idiossincrasias nos compassos finais. Guerra Peixe, Peça para dois minutos (c. $52-61)$.

Guerra-Peixe, em carta a Curt Lange, afirma que, na Peça para dois minutos, “[...] a série......[sic] é de DEZ sons. Levo em conta mais o elemento formal (com características nacionais) do que a técnica schoenbergueana [sic], propriamente" (Guerra-Peixe 1947 apud Lima 2002, p. 147, grifo do autor). Em seguida, ele apresenta a série, composta pelas notas E-A-F\#-A\#-C\#-B-G-D-F-Eb, todas distintas entre si. Ainda assim, o uso da série de dez notas também não é feito de maneira a mantê-la intacta, portanto, não é rigorosamente "schoenberguiana"; ao menos há diversas fragmentações da série (ou seja, sem a necessidade de rigorosamente 
expor as dez notas antes de poder repetir alguma). A evidência disso ocorre já no começo, onde as seis primeiras notas são exatamente transpostas (i.e., sem alteração mínima de qualquer um dos intervalos internos do agrupado) uma $6 \mathrm{~m}$ abaixo nas seis notas conseguintes, e já com a repetição da $6^{\underline{a}}$ e da $8^{\underline{a}}$ notas dentre essas doze primeiras. Mais ainda: é visível que nos agrupamentos de seis notas ao longo da obra, que vem da série, geralmente (com exceções, como no c. 14, Fig. 3) o perfil traçado dos intervalos $4 \mathrm{~J}, 6 \mathrm{~m}$ e $2 \mathrm{M}$ nesta ordem de aparição (no $1^{\circ}$, $2^{\underline{o}}$ e $3^{\mathrm{o}}$ par dentre as seis notas, respectivamente), onde eventualmente a $4 \mathrm{~J}$ é substituída por $5 \mathrm{~J}$, a $6 \mathrm{~m}$ por $3 \mathrm{M}$ (menos frequentemente por $3 \mathrm{~m}$, que também advém do intervalo entre as $2^{\underline{a}}$ e $3^{\underline{a}}$ notas, assim como entre as $4^{\underline{a}}$ e $5^{\underline{a}}$ notas), e a $2 \mathrm{M}$ por $2 \mathrm{~m}$. Com alguma frequência, um destes três intervalos é omitido nos agrupamentos de 4 notas, mas a ordem $(4 \mathrm{~J}, 6 \mathrm{~m}, 2 \mathrm{~m})$ é quase sempre mantida (com exceções raras, vide o c. 15, Fig. 3). Outra evidência cabal da liberdade estrutural acontece ao final da obra, a partir do c. 57 (Fig. 8), onde o segundo grupo de seis notas sofre uma transposição exata de $2 \mathrm{M}$ acima da sua conformação original do c. 2, e no c. 60 (Fig. 8), onde há este mesmo grupo com uma outra transposição também exata. Isso mostra que a fragmentação dessas seis notas iniciais específicas, nestes trechos, seria um processo composicional mais relevante do que o encontro da série de dez sons. No fim, as duas células que compõem a série, a primeira formada por a1 e outro a1 alterado, e a segunda por b1, são as fragmentações que geram os processos mais significativos.

Ainda assim, uma busca paralela na partitura revela que a série original de dez notas mantém fixa e exata a disposição que mais se repete durante a peça. O mais interessante é observar que a aparição da série não acontece na exposição "temática" inicial e nem em outras recapitulações (de textura em oitavas), e sim no primeiro episódio polifônico, de característica contrapontística e de desenvolvimento, a partir do c. 6 (Fig. 9). Portanto, a série é geradora de motivos e também um estruturante mínimo comum à peça toda (como se fosse um "DNA"), mas não tem o papel de sinalização temática, i.e., não compõe as ideias principais da peça, e por isso mesmo não tem a pretensão de se fazer percebida ou memorizada. 

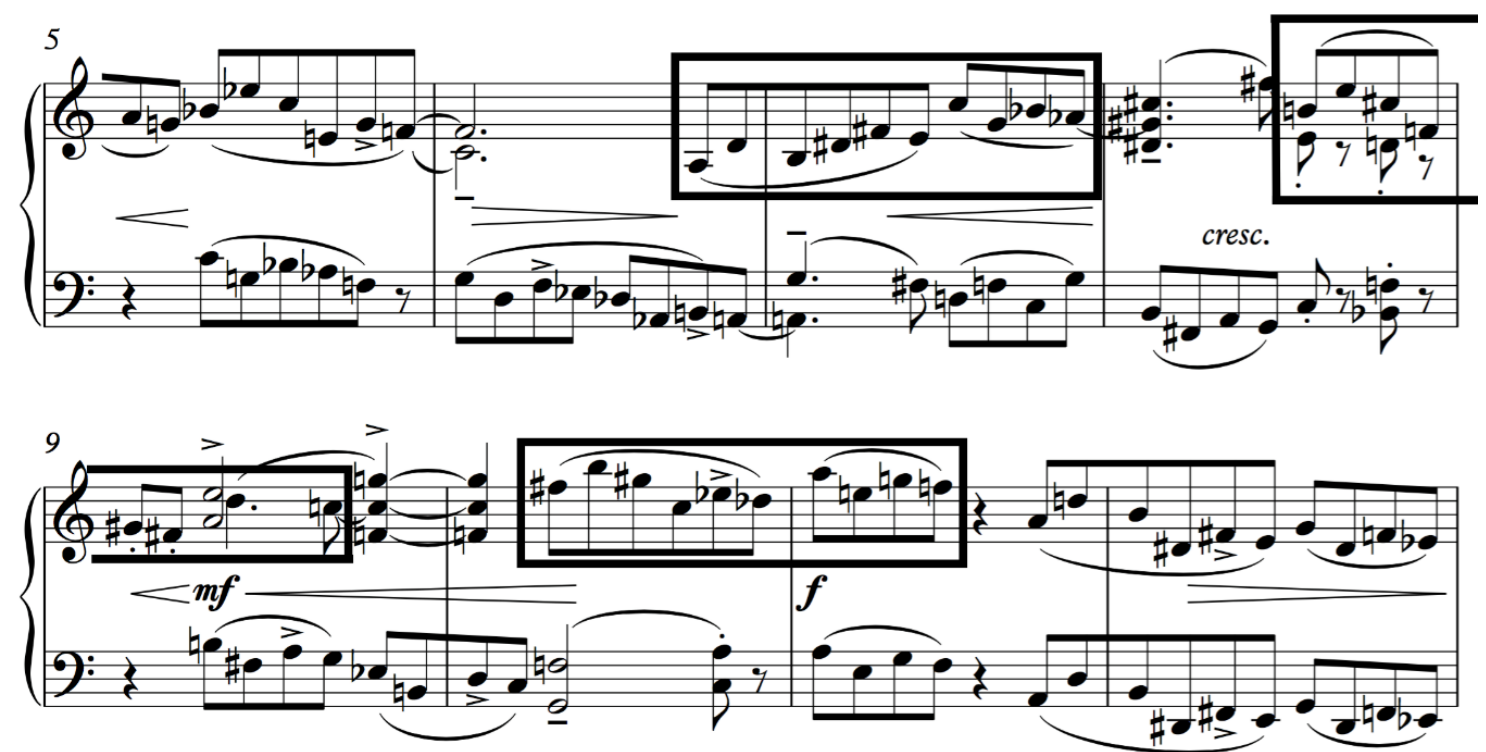

Figura 9: Primeiras aparições da série em sua integralidade. Guerra Peixe, Peça para dois minutos (c. 5-12).

A postulada série algumas vezes sofre pequenas alterações, apesar de aparecer inteira, como nos c. 8-9 (Fig. 9), onde a última nota dela esperada é omitida (Bb). Isso ocorre também no c. 19 (a partir do Ab, Fig. 10), onde as duas notas finais da série (A e G) são aparentemente omitidas, embora havendo a possibilidade de se interpretar a antecipação delas em um acorde na região aguda, que é tocado simultaneamente ao começo dessa série. Outro desses casos também ocorre nos c. 23-25 (Fig. 10), onde a nota final é convenientemente alterada em um semitom acima, justamente na entrada da temática de ritmo brasileiro. Essa alteração serve para corroborar com a sensação de melodia nacional, sugerida pelo modo mixolídio em $\mathrm{B} b$ (que começava a entrar nas preocupações composicionais de Guerra-Peixe, conforme atesta a carta para Curt Lange anteriormente citada). Mais uma vez, isso reflete a dispensa do rigor matemático, para o qual a atonalidade é tão propícia.

Na parte B, a série postulada sofre uma fragmentação da sua continuidade linear, mudando bruscamente de tessitura (dividindo os grupos de seis e quatro notas contidos na série) e passando de uma mão à outra do piano (Fig. 11). Aparentemente, o andamento mais lento oferece melhor essa possibilidade de quebra na continuidade das linhas, contrastando as regiões grave e aguda no meio desse fluxo de semínimas, entre os c. 35-39, tendo em vista que no resto da peça, essa troca abrupta não parece ocorrer, nem mesmo nos c. 53-56 (Fig. 8), 
MUSICA THEORICA Revista da Associação Brasileira de Teoria e Análise Musical 2020, v. 5, n. 2, p. 207-225 - Journal of the Brazilian Society for Music

onde as linhas se imitam ritmicamente, mas não oferecem continuidade melódica de uma linha à outra (e tampouco exibem a série integralmente).

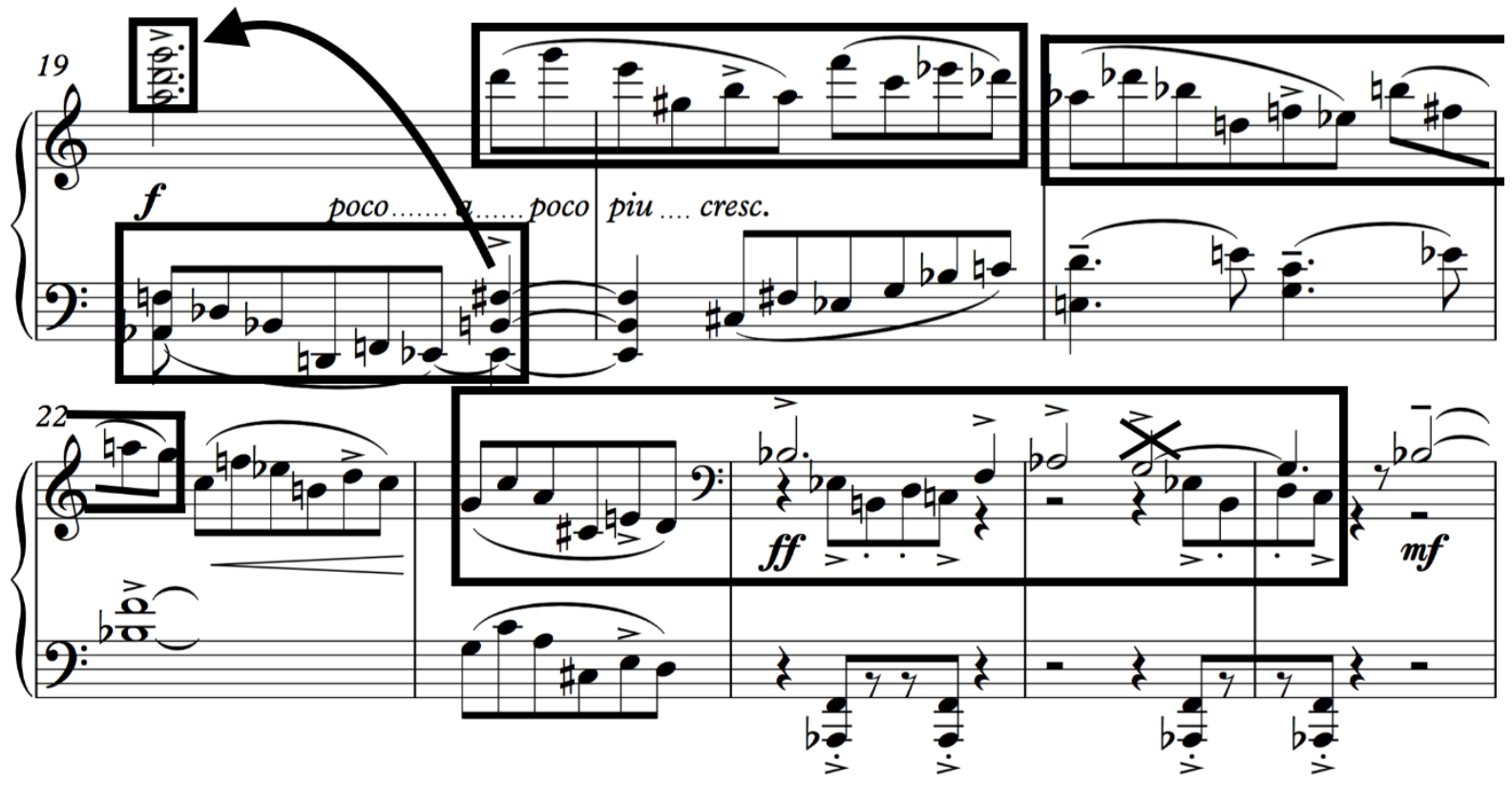

Figura 10: Aparições consecutivas e alterações da série postulada. Guerra Peixe, Peça para dois minutos (c. 19-26).

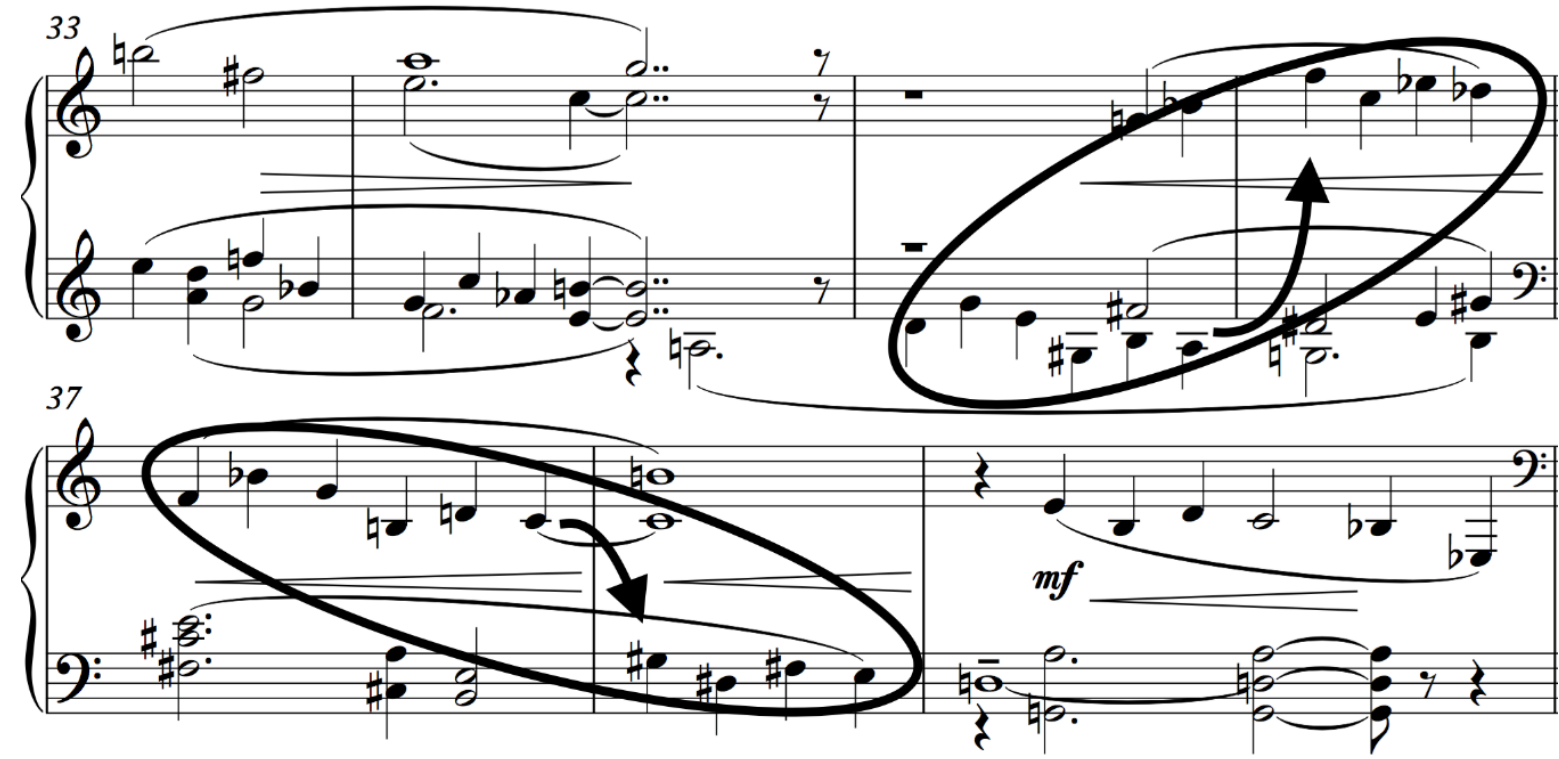

Figura 11: Aparições diagonais da série postulada na parte B. Guerra Peixe, Peça para dois minutos (c. 33-39). 
$\mathrm{Na}$ recapitulação modificada de $\mathrm{A}\left(\mathrm{A}^{\prime}\right)$, essa série reaparece, integralmente, mais umas poucas vezes, mas na última das aparições advém um fenômeno típico do desenvolvimento de Fugas5, e que sugere um acúmulo de energia ao longo da obra: a culminância em uma espécie de stretto ${ }^{6}$, que se aplica aqui com própria a série ao invés do que seria o sujeito em uma Fuga, i.e., apresentando um contraponto entre a série e outra transposição dela mesma, sob entradas a uma separação métrica de quatro notas de semicolcheia (c. 51-53, Fig. 12). A única alteração é na ordem invertida entre as duas primeiras notas da série mais aguda, anacruse do c. 52. A razão do compositor escolher essa alteração pode ser aventada em poucas suposições: ele estaria evitando a percepção evidente da imitação entre as linhas (que também revelaria a série, sendo que ela não deveria ter a função de uma ideia temática principal); ou simplesmente por alguma preferência harmônica pessoal.

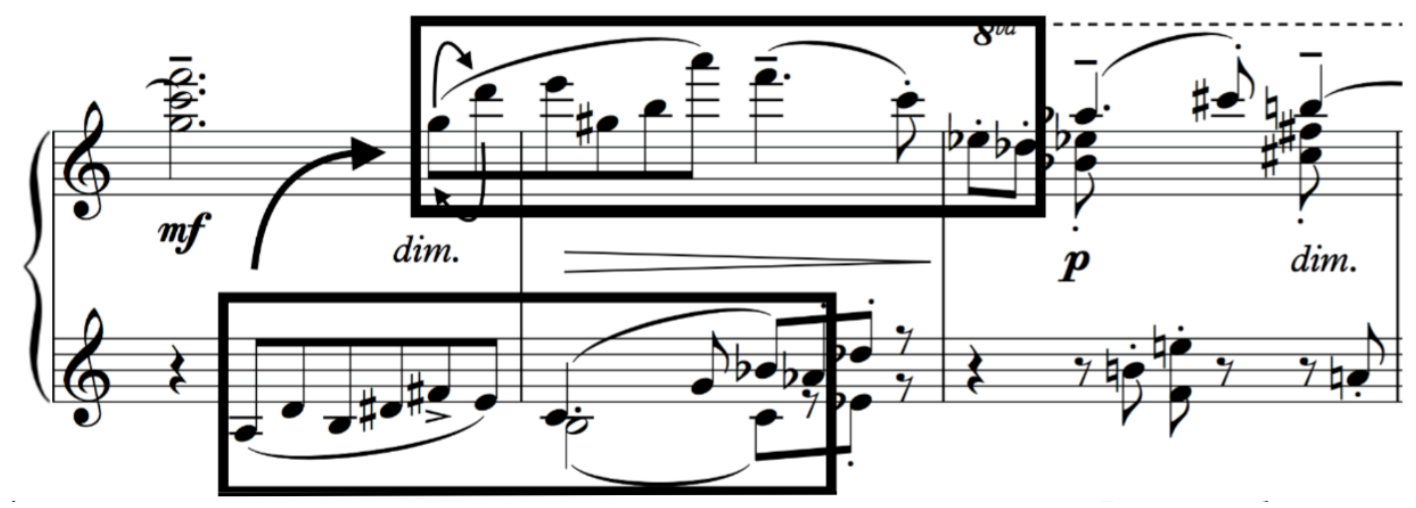

Figura 12: Última aparição da série postulada, em forma de stretto. Guerra Peixe, Peça para dois minutos (c. 51-53).

Uma relação importante com o variado conjunto de dinâmicas da peça é visível pela demarcação de $f$ em todo lugar onde o material se encontra mais parecido com o inicial, o que lhe atribui forte característica temática principal (embora sempre com mais liberdade do que em uma forma tradicional), reafirmado pela textura monofônica em oitavas. $\mathrm{O}$ interesse disso decorre da ideia de que vários tipos de desenvolvimento da peça traçam um perfil que vão

\footnotetext{
${ }^{5}$ Cf. Zamacois 2007, p. 57.

${ }^{6}$ Ibid., p.70.
} 
do $p$ (em textura predominante polifônica) ao $f$ (atingido predominantemente como o perfil temático principal do início, e por isso predominantemente na textura em oitavas); com essa técnica, gera-se uma tensão direcionada ao encontro de um clímax, que serve para a recapitulação temática (anacruse do c. 5 ao c. 11, cf. final da Fig. 1 e continuação na Fig. 2). Uma única exceção ocorre nos c. 19-23 (Fig. 5), quando a dinâmica $f$ em textura quase integralmente polifônica conduz ao perfil de ritmo brasileiro, atingido em intensidade ff no c. 24 (Fig. 5). Isso parece se justificar pelo trecho cumprir uma função, a de transição para alcançar o ff. No c. 40 (Fig. 6), o perfil rítmico identificado com brasilidade é reexposto, novamente marcado pelo ff, e se forem considerados essa sua repetição, o seu contraste de articulação (único lugar da obra em que se aplica o staccato, salvo nos c. 53-56 (Fig. 8), onde se aproveita o efeito de ressonância da região aguda do piano, pela falta de abafadores aos martelos dessa região do instrumento), a sua dinâmica sem paralelo na peça (a mais intensa, ff), a sua disposição na tessitura mais grave da peça, e por fim a sua função de fechamento das seções A e B, haverá então base sólida o suficiente para destacar essa ideia temática como relevante, e portanto sendo um perfil temático auxiliar.

\section{Considerações finais}

Embora esta peça se insira em uma fase da vida composicional de GuerraPeixe caracterizada como dodecafônica ${ }^{7}$, não muito após os seus estudos com Koellreuter, elementos da Peça para dois minutos como o uso de harmonias quartais, a repetição pouco previsível de notas, a manutenção de intervalos específicos em diversas transposições de certos motivos, a evidência de uma série de dez notas (ao invés das doze previstas pelo dodecafonismo), e as liberdades de alterações e fragmentações dos motivos e séries demonstram que o compositor esteve interessado em experimentar em uma estética atonal mais livre, mesmo ainda possuindo diversos pontos de sonoridade em comum com o dodecafonismo (especialmente em situações nas quais as harmonias quartais e o agregado (012), dispostos em acordes homofônicos, se sucedem sem temor ao contraste de aspereza, tal qual pregaria a ideia de "emancipação da

\footnotetext{
${ }^{7}$ Guerra-Peixe (1971, p. 23-43).
} 
dissonância"8, como acontece nos c. 10, 16, 33, entre outros). As preocupações de estética nacional também começam a aparecer, ainda que lhe gerassem conflitos pessoais acerca de suas decisões artísticas (visto cogitar a aproximação do público, as características da música brasileira, e a modernização da linguagem harmônica, fatores estes que se servem de aparências contraditórias entre si).

Ao mesmo tempo, vimos que, no fundo, um único motivo ofereceu possibilidades de variação suficientes para estruturar a peça toda, em conjunto a um segundo motivo que, por sua vez, é de fato derivado do primeiro. Fica claro que não há o interesse em gerar as developing variations aqui, dado que estas se adequam a peças de tamanho muito mais ambicioso, onde, através de um desenvolvimento de tradição germânico-romântica, se desgarrar das ideias iniciais torna-se um dado necessário e desejado. Aqui, o motivo, a1, por mais variado que seja, nunca some de vista, sendo até um fator mínimo de coesão da peça - e talvez mais do que a própria série, já que b1 também se erige como uma derivação imediata de a1.

Por fim, o uso particular das dinâmicas e das diferenças de articulação e de textura cria contrastes e direcionalidades que demonstram um tipo de pensamento bastante estrutural, ligado a toda a história das pequenas formas pianísticas, remontando à forma ternária, à Fuga, ao Estudo e à Miniatura. A disposição didática dos elementos formais auxilia na compreensão do ouvinte acerca das intenções musicais de cada ideia da peça. Mesmo com a ausência de um tema tradicional, evidente em sua fraseologia, o perfil temático ainda é sentido, e reforça-se por uma textura própria (em oitavas), uma dinâmica de maior destaque e por recapitulações que conservam essas qualidades.

\section{Referências bibliográficas}

1. Barros, Frederico M. 2013. César Guerra-Peixe: A modernidade em busca de uma tradição. Tese (Doutorado). São Paulo: Faculdade de Filosofia, Letras e Ciências Humanas, Universidade de São Paulo.

2. Guerra-Peixe, César. 1947. Carta a Curt Lange (15/04/1947). Rio de Janeiro: Acervo Curt Lange, UFMG.

\footnotetext{
${ }^{8}$ cf. Schoenberg (1950, p. 104-105).
} 
MUSICA THEORICA Revista da Associação Brasileira de Teoria e Análise Musical 2020, v. 5, n. 2, p. 207-225 - Journal of the Brazilian Society for Music

3. __. 1949. Carta a Curt Lange (02/07/1949). Rio de Janeiro: Acervo Curt Lange, UFMG.

4. __. 1971. Dossiê. Rio de Janeiro: texto datilografado.

5. Kostka, Stefan; Santa, Mathew. 2018. Materials and Techniques of Post-Tonal Music. 5 ed. NY: Routledge.

6. Lima, Cecília N. 2002. A Fase Dodecafônica de Guerra-Peixe; à luz das impressões do compositor. Dissertação (Mestrado). Campinas: Instituto de Artes, Universidade Estadual de Campinas.

7. Sampson, Brook. 1911. Outline Analysis of each of J. S. Bach's Forty-Eight Fugues in the "Das Wohltemperirte Clavier". London: The Vincent Music Company.

8. Schoenberg, Arnold. 1950. Style and Idea. New York: Philosophical Library, Inc.

9. __. 2008. Fundamentos da composição musical. São Paulo: Edusp.

10. Straus, Joseph. 2016. Introduction to post-tonal theory. 4 ed. NY: W. W. Norton.

11. Rossi, Hanon. 2019. As articulações da estrutura polifônico-textural em "Musique Funèbre", de W. Lutoslawski. Dissertação (Mestrado). São Paulo: Escola de Comunicações e Artes, Universidade de São Paulo.

12. Zamacois, Joaquín. 2007. Curso de formas musicales. Madrid: Mundimúsica Ediciones. 